\title{
Reviews
}

\section{Considerations for successful transplantation of encapsulated pancreatic islets}

\author{
P. de $\operatorname{Vos}^{1}$, A.F.Hamel ${ }^{1}$, K. Tatarkiewicz ${ }^{2}$ \\ ${ }^{1}$ Department of Pathology and Laboratory Medicine, Section of Medical Biology, University of Groningen, Groningen, \\ The Netherlands \\ ${ }^{2}$ Research Division, Joslin Diabetes Center, Boston, Massachusetts, USA
}

\section{Abstract}

Encapsulation of pancreatic islets allows for transplantion in the absence of immunosuppression. The technology is based on the principle that transplanted tissue is protected for the host immune system by an artificial membrane. Encapsulation offers a solution to the shortage of donors in clinical islet transplantation because it allows animal islets or insulin-producing cells engineered from stem cells to be used. During the past two decades three major approaches to encapsulation have been studied. These include intravascular macrocapsules, which are anastomosed to the vascular system as AV shunt; extravascular macrocapsules, which are mostly diffusion chambers transplanted at different sites; and extravascular microcapsules transplanted in the peritoneal cavity. The advantages and pitfalls of these three approaches are discussed and compared in the light of their applicability to clinical islet transplantation. All systems have been shown to be successful in preclinical studies but not all approaches meet the technical or physiological requirements for application in human beings. The extravascular approach has advantages over the intravascular because since it is associated with less complications such as thrombosis and infection. Microcapsules, due to their spatial characteristics, have a better diffusion capacity than macrocapsules. Recent progress in biocompatibility of microcapsules has brought this technology close to clinical application. Critical issues such as limitations in the functional performance and survival are being discussed. The latest results show that both issues can be solved by the transplantation of microencapsulated islets close to blood vessels in prevascularized solid supports. [Diabetologia (2002) 45: 159-173]

Keywords Transplantation, encapsulated pancreatic islets.
A major challenge in the treatment of Type I (insulindependent) diabetes mellitus is the prevention of late complications, and thereby improvement of the quality of patient life. There is no dispute that euglycae-

Received: 5 September and in revised form: 18 October 2001

Corresponding author: P. de Vos, Department of Pathology and Laboratory Medicine, Section of Medical Biology, University of Groningen, Hanzeplein 1, 9700 RB Groningen, The Netherlands, e-mail: P.DE.VOS@MED.RUG.NL

Abbreviations: a-FGF Acidic-fibroblast growth factors; ePTFE expanded polytetrafluoroethylene; G, guluronic acid; HEMA, 2-hydroxyethyl methacrylate; $M$, mannuronic acid; PANPVC, poly acrylonitrile and polyvinylchloride copolymer; PLL, poly-L-Lysine mia is of essential importance to reach that goal. Euglycaemia can be achieved by insulin treatment and the results of the Diabetes control and complications trial clearly show that insulin treatment delays the onset and reduces the progression of diabetic complications [1]. Intensified treatment, however, is not a simple chore because it requires multiple daily injections, frequent monitoring, dosage adaptations and, thus, patient compliance. It is also associated with frequent episodes of severe hypoglycaemia and with glycaemic unawareness. A different approach to euglycaemia is to provide the diabetic patient with an endogenous rather than an exogenous source of insulin by the transplantation of the endocrine pancreatic tissue. Pancreatic organ transplantation is now an es- 
tablished mode of treatment with 15000 cases worldwide $[2,3]$. Results have substantially improved during the past two decades and the current patient and graft survival rates almost equal those of kidney transplantation. A successful pancreas transplant provides almost normal glucose homeostatis but it requires lifelong immunosuppressive medication. It is still not clear whether the advantages of a pancreas transplant over continued insulin treatment outweighs the disadvantage of obligatory immunosuppression. Most transplant centres still restrict themselves to combined pancreas and kidney transplantation in diabetic patients with end-stage renal failure $[2,4]$. Islet transplantation, in contrast to pancreas transplantation, requires no major surgery. Moreover, successful islet transplantation without immunosuppression might be achieved by relatively simple methods as immunoisolation by encapsulation. Such an approach utilizes a semipermeable membrane which forms a mechanical barrier separating the graft from the host antibodies and immune cells but allows for the diffusion of glucose, insulin, nutrients and islet waste products.

\section{Macroencapsulation of pancreatic islets}

The two major encapsulation systems are macroencapsulation and microencapsulation. In the first one, the macrodevices contain many islets in one immunoisolating membrane. The intravascular device is usually composed of a microporous tube with blood flow through its lumen and with a housing on its outside containing the implanted tissue $[5,6]$. The device is implanted into the vessels of the host by vascular anastomoses. The concept of extravascular devices does not require vascular anastomoses because it is based on the principle of diffusion chambers [7]. The geometry could be planar in the form of a flat, circular double layer or tube-like as a so-called hollow fibre [7].

The most intensively studied intravascular device is the modified diffusion chamber of Chick et al [8]. It is technically advanced and has been tested extensively in small [9] as well as in large animals [9, 10]. The original device was composed of a number of small diameter artificial capillaries contained by one large diameter tube. The artificial capillaries were composed of polyacrylonitrile and polyvinylchloride copolymer (PAN-PVC) ultrafiltration capillaries [11], and the remaining lumen of the large diameter tube, ie. the outside of the artificial capillaries, was loaded with hormone producing cells. The design allows close contact between the islets and blood which are separated only by the microporous walls of the capillaries. These devices were found to induce normoglycaemia in diabetic rats [9], dogs [10] and monkeys [9] but required systemic anticoagulation. The duration of this normoglycaemia was usually restricted to several hours and successes of a somewhat longer duration were exceptional. Clotting of the blood in the lumen of these small diameter artificial capillaries proved to be a major obstacle, in spite of anticoagulant medication in massive doses. This thrombus formation was an early sign of insufficient biocompatibility and has led to the use of tubular membranes with larger diameters in the hope of minimising or eliminating clot formation in the absence of systemic anticoagulation. The present device is composed of a single, coiled and tubular membrane with an internal diameter of 5-6 $\mathrm{mm}$. The membrane has been modified but is still composed of PAN-PVC with a nominal molecular weight cutoff of $50 \mathrm{kD}$. This approach was found to be rather successful because these devices implanted as high flow arteriovenous fistulas could remain patent for periods of 7 weeks in the absence of systemic anticoagulant therapy [12]. This success can be explained in part by the high flow rates through the device which prevents adhesion of cells to the membranes or collection of those cells in the immediate vicinity [13]. However, high flow arteriovenous fistulas are not without risk and much longer patency rates are required for effective applicability. Obviously, more thromboresistant materials are required for this type of device.

Although the intravascular devices have shown some degree of success, the problems mentioned above should be solved if clinical application is considered. Even then, the complications associated with any type of vascular prosthetic surgery - such as thrombosis, either primary or secondary to intimal hyperplasia at the venous anastomosis, defects of the device, or infection - remain a serious threat. This is a major drawback for application in large numbers of diabetic patients.

The surgical risks are much lower with extravascular than with the intravascular devices. Biocompatibility problems are usually deleterious only to the function of the encapsulated tissue and have no or only minimal risk for the recipient. The relative safety is an important advantage of extravascular over intravascular devices but the interactions of tissue-material are of similar complexity. These biocompatibility problems are usually related to toxicity and activation of non-specific foreign body reactions resulting in fibrotic overgrowth with subsequent necrosis of the encapsulated tissue.

Macrocapsules can be implanted with minimal surgery in different sites such as the peritoneal cavity [14-17], the subcutaneous site [18-24], or the renal capsule [25]. They can also be readily retrieved and produced in a relatively simple way.

Many different biomaterials have been applied for the production of macrocapsules. The most commonly applied are nitro-cellulose acetate [26], 2-hydroxyethyl methacrylate (HEMA) [27], acrylonitrile and 
sodium-methallylsulfonate [28], and alginate [29]. The hollow fibre geometry is usually preferred over the planar membranes for their smaller foreign body response [30]. Most studies on hollow fibres use fibres made of PAN-PVC $[13,31]$, similar to those used in intravascular devices. They have been produced with a smooth and fenestrated outer skin with the same spongy matrix as applied in the intravascular. The design with the smooth outer skin proved to be the most successful because it provokes much less fibrosis than the rough fenestrated surface which allows host tissue to grow into the spongy matrix. Many modifications of this concept have been proposed in order to further improve the biocompatibility. One of those was the coating of the membranes with poly(ethyleenoxide) to reduce protein adsorption [32].

Initial studies with macrocapsules were not very successful. This was not so much the consequence of fibrotic overgrowth but rather of aggregation of the encapsulated tissue into large clumps [18]. Extensive necrosis occurred in the centre of the clumps as a result of diffusion limitations for nutrients. This problem was readily solved by preventing contact between the encapsulated tissue elements through permanent solitude immobilization in a matrix such as collagen [33, 34], Ca-alginate [18], or chitosan [11]. Usually in PAN-PVC fibres islets are immobilized in alginate. The islet density is kept quite low and never exceeds $5-10 \%$ of the volume fraction because viability has been found to be substantially reduced with higher densities. When transplanted in $B B$-rats, islets encapsulated in fibres were found to induce normoglycaemia for up to 8 months but glucose tolerance remained disturbed and decreased rapidly with time, in spite of prolonged normoglycaemia [31, 35]. A major factor is that hollow fibres, as a consequence of their shape, tend to break when forced to bend under physiological stress $[11,36]$. Another factor is the low number of islets implanted which could be insufficient for achieving long-term graft survival. The use of higher numbers, however, is impractical because enormous lengths of fibres would be required as a consequence of the low seeding density of the membranes. A modification was to use tubes with a wider lumen of several millimetres. This, however, is associated with a substantial increase in diffusion distance, which enhances rather than reduces problems such as necrosis as a consequence of insufficient nutrient supply, and accumulation of waste materials. Some success with these devices has been reported in diabetic rats, but extreme amounts of islets, ie. 30000 islets $/ \mathrm{kg}$, were required to maintain normoglycaemia for only a few months [36]. In addition, after intraperitoneal implantation, the membranes still provoked a foreign body reaction which resulted in overgrowth by a thin, but avascular fibrotic cellular infiltrate, which implies further limitations in the diffusion capacity and in the life span of the islets.
During the past few years, an interesting trend has been the growing number of groups applying hydrogels for macroencapsulation. Hydrogels provide a number of features which are advantageous for the biocompatibility of the membranes. Firstly, as a consequence of the hydrophilic nature of the material, there is almost no interfacial tension with surrounding fluids and tissues which minimises the protein adsorption and cell adhesion. Furthermore, the soft and pliable features of the gel reduce the mechanical or frictional irritations to surrounding tissue. And, finally, they provide a high degree of permeability for low molecular weight nutrients and metabolites, which is required for the optimal functioning of living cells.

Many hydrogels have been applied, such as gels prepared from alginate [37-39], agarose [17, 40], HEMA [27, 41] and a copolymer of acrylonitrile and sodium-methallyl sulphonate, AN69 [28]. Primary attention has been focussed on the hydrogel membrane AN69, which induced only minimal fibrosis in the peritoneal cavity of rats [42, 43] but had low permeability for insulin $[42,43]$. Recently, Corona discharge has been introduced to obtain a membrane with a more hydrophobic surface $[42,43]$. Fewer molecules adhered to the surface of such membranes, improving not only the permeability for insulin but also its longterm biocompatibility. One year after implantation in rats, only a few macrophages were found on the membranes' surface. Moreover, encouraging results were reported by Jain et al who demonstrated functional porcine islets transplanted in agarose macrobeads almost 200 days after intraperitoneal transplantation into $B B$ rats [28].

\section{Microencapsulation of pancreatic islets}

Microencapsulation is the technique by which each islet is enveloped in its own, spherical semipermeable membrane. Several arguments favour microcapsules over macrocapsules. Their spherical shape offers better diffusion capacity because of a better surface-tovolume ratio. Microcapsules cannot be easily disrupted, are mechanically stable, do not require complex or expensive manufacturing procedure, and can be implanted into the patient by a simple injection procedure.

Reportedly, the clinical experience is still restricted to one recipient [44] but several research groups are concentrating on transplantation of microencapsulated islets in the experimental setting [45] [22, 23, 46, 47, 47-68]. Although successful encapsulated islet grafts do induce normoglycaemia in streptozotocin diabetic rodents recipients, some authors have reported reduced functional performance in response to glucose challenge [59, 69-72].

For several years, we have concentrated on microencapsulation and we have directed our efforts to 
a stepwise analysis of the factors influencing performance of the microencapsulated grafts. To this end, we have been using only one technique of alginatepolylysine microencapsulation as initially introduced by Lim and Sun [73], instead of testing other materials in a trial and error approach. Our aim is to define the conditions which must be met for successful transplantation of microencapsulated islets as a feasible treatment of Type I diabetes mellitus.

\section{Technical considerations for the production of microcapsules}

Microcapsules are almost exclusively produced from hydrogels, and Table 1 lists the most popular biomaterials applied in this technique. A major distinction exis between water soluble polymers such as alginates and water insoluble polymers such as HEMAMMA. Water insoluble polymers are preferred by a number of groups [41, 74-76] because they are assumed to be more stable than water soluble polymers after implantation. However, a major obstacle in using water insoluble polymers for encapsulation of cells is the use of an organic solvent, which usually interferes with cellular function $[41,77]$.

We, like others $[62,67,68,78-80]$, have concentrated on alginate-based capsules because they have consistently been found not to interfere with cellular function. Despite their solubility in aqueous solutions, they have been shown to be stable for years in small and large animals and recently also in human beings. The most commonly used alginate-based capsules are formed by the alginate-polylysine system. The technique is based on entrapment of individual islets in an alginate droplet which is transformed into a rigid bead by gelification in a divalent cation solution, mostly rich in $\mathrm{Ca}^{2+}$. Alginate-molecules are composed of mannuronic (M) and guluronic acids (G). In the first step of the microencapsulation process (ie. the gelification) the alginate-molecules are connected by $\mathrm{Ca}^{2+}$ through binding of consecutive blocks of G-molecules on each of both molecules. After gelification the beads are coated with a polylysine membrane by suspending the beads in a poly-L-lysine (PLL) solution. During this step, PLL binds to mixed sequences of $\mathrm{G}$ and $\mathrm{M}$ in the alginate molecules [81, 82]. This induces the formation of complexes at the capsule surface consisting of $\alpha$-helical PLL surrounded by superhelically orientated polysaccharide chains [82]. The presence of these complexes decreases the porosity of the membrane. By varying the molecular weight and the concentration of the polylysine, and the incubation time the porosity of the capsule membrane can be modulated [58, 83-88]. Usually, $10 \mathrm{~min}$ incubation in $0.1 \%$ polylysine with a molecular weight of $22 \mathrm{kDa}$ is sufficient to form an immunoprotective membrane. However, binding of polylysine
Table 1. Main components of capsules proposed for microencapsulation of pancreatic islets

\begin{tabular}{|c|c|c|}
\hline $\begin{array}{l}\text { Main component of the } \\
\text { capsule }\end{array}$ & Source & Initially proposed by \\
\hline Alginate & Alga & Lim and Sun 1980 [73] \\
\hline Chitosan & Alga & Zielinski 1994 [131] \\
\hline Agarose & Alga & Iwata et al. 1989 [60] \\
\hline $\begin{array}{l}\text { Poly(hydroxyethylmet- } \\
\text { acrylate-methyl methacry- } \\
\text { late)(HEMA-MMA) }\end{array}$ & Synthetic & Dawson et al. 1987 [132] \\
\hline $\begin{array}{l}\text { Copolymers of acryloni- } \\
\text { trile (AN69) }\end{array}$ & Synthetic & Kessler et al. 1991 [28] \\
\hline Polyethyleneglycol (PEG) & Synthetic & Cruise et al. [48] \\
\hline
\end{tabular}

does not only depend upon the incubation time and the molecular weight of the polylysine but also on the type and concentration of alginate [87, 89] as well as on the temperature of an incubation [86, 87, 89]. In a final step to provide biocompatibility, the capsules are suspended in a solution of alginate or other negatively charged molecules [86, 89] to bind all positively charged polylysine residues still present at the capsule surface.

Another very important aspect of adequate biocompatibility, which requires a lot of experience in microencapsulation process, is a smooth and mechanically stable microcapsule. In our laboratory we have observed that high rather than low viscosity alginates produce smooth beads with no obvious tails or strains. Moreover, we have found that after implantation, alginates with low-G concentrations had a tendency to swell with subsequent breakage of the PLL membrane followed by cellular overgrowth of the capsules. Therefore, for our studies we have chosen the alginate with an intermediate G-concentration.

The stability of a capsule is determined by stability of a membrane and stability of an alginate core. The stability of a membrane can be controlled by the PLL-step because shorter incubation time, lower PLL concentrations, and lower PLL molecular weight than described above, were associated with an increase of the number of capsules with broken membranes. Additionally, incubation at $4{ }^{\circ} \mathrm{C}$ instead of room temperature led to less stable microcapsules. Finally, we did not apply EGTA or citrate [77] to liquify the inner core of the capsule. The reason for this modification of the original method [73] was that many capsules were observed to lose their integrity during the treatment. In spite of all the improvements in the stability of the capsules, tissue reactions still continued to interfere with longevity of the graft survival. We have found that other factors, not directly related to the production procedure, were responsible for the tissue reaction as signalling insufficient biocompatibility of microcapsules. 


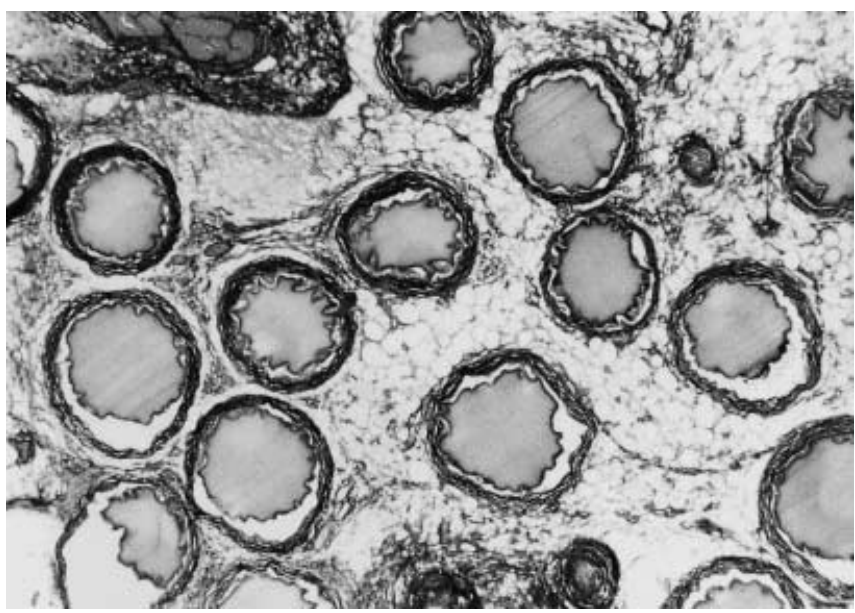

Fig. 1. Alginate-polylysine capsules after provoking a foreign body reaction in the peritoneal cavity of an $\mathrm{AO}$ rat. At 1 month after implantation the capsules adhere to the omentum and overgrown by fibroblasts. (GMA-embedded section, syrius red staining, original magnification $\times 50$ )

\section{The biocompatibility issue l: chemistry of the capsule}

Failure of microencapsulated islet grafts is usually interpreted as the consequence of insufficient biocompatibility, which induces a non-specific foreign body reaction against the microcapsules and results in progressive fibrotic overgrowth of the capsules (Fig.1). This overgrowth interferes with adequate nutrition of the islets and consequently causes islet cell death.

We have tested the hypothesis that the lack of biocompatibility is caused by impurities contaminating the alginate. Alginates are crude products extracted from alga and contain several substances which are known to provoke inflammation [59, 87, 90-92]. Therefore, we designed the purification procedure, which is basically composed of a filtration step, an extraction step, and a dialysis step. The procedure is associated with a loss of $25 \%$ to $40 \%$ of the alginate but it had no influence on its chemical composition $[59,93]$.

Empty capsules prepared of either crude or purified alginate were implanted in the peritoneal cavity of normoglycaemic $\mathrm{AO} / \mathrm{G}$ rats and retrieved by peritoneal lavage at varying time points after implantation. Crude alginate capsules were always overgrown by fibrotic tissue. In contrast, $80 \%$ to $100 \%$ of the purified capsules could routinely be retrieved up to 12 months after implantation, and less than $10 \%$ of those retrieved capsules showed fibrotic overgrowth (Fig. 2). Similarly to empty capsules, capsules containing islets and prepared from purified alginate were found to be adequately biocompatible. After allotransplantation and isotransplantation, the majority was found freely floating in the peritoneal cavity and $80 \%$ to $100 \%$ of capsules could be recovered and less than $10 \%$ of retrieved microcapsules showed signs of fibrotic overgrowth.

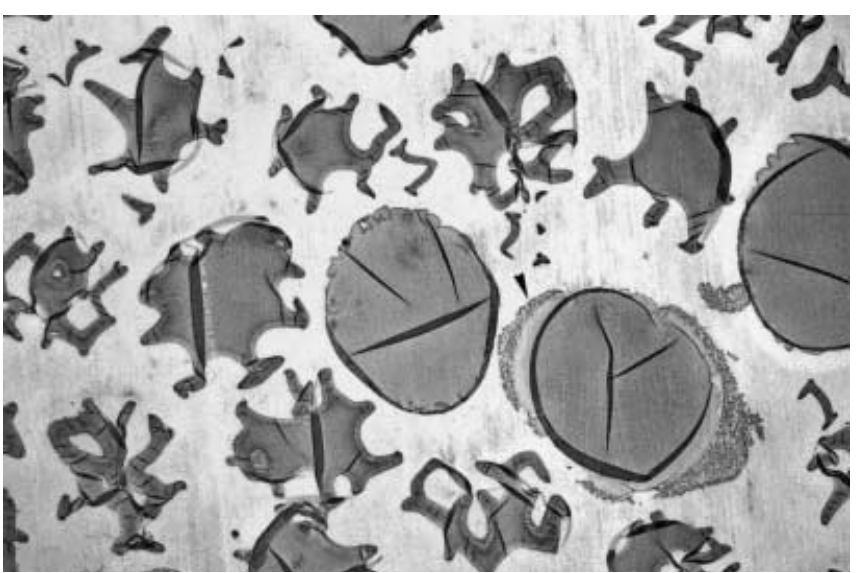

Fig. 2. Alginate-polylysine capsules prepared from purified alginates. Capsules were retrieved at 12 months after implantation in the peritoneal cavity of AO rats. The arrow indicates one of the few capsules with fibrotic overgrowth (GMA-embedded section, Romansky-Giemsa stain, original magnification $\times 50)$. Capsules are deformed as the consequence of inhomogeneous water extraction during processing for histology

We have also studied the biocompatibility of alginates composed of different proportions of guluronic acid blocks $(\mathrm{G})$ to mannuronic acid blocks (M). Empty capsules with varying G/M ratio were implanted into the peritoneal cavity. We found that the biocompatibility of alginate-polylysine capsules strongly depends on the alginate G-content. Empty capsules prepared from high-G alginate provoked a severe inflammatory response, while capsules prepared from alginates with an intermediate G-content remained free of overgrowth. This could be due to different binding properties of polylysine to high-G and intermediate-G alginates [90]. When inadequately bound to alginate, polylysine can be a strong initiator of fibrosis. This was shown by others [94] and by us [90] when comparing the biocompatibility of high-G alginate-polylysine capsules and high-G alginate beads in the absence of polylysine. The high-G beads remained free of any obvious overgrowth while all of high-G alginate-polylysine capsules were overgrown by several layers of fibroblast within the first month of implantation in AOrats.

In summary, our findings show that purification of alginate is associated with a clear-cut and long-lasting improvement in biocompatibility. They also show that the majority but not all capsules stay free of fibrotic overgrowth. A small minority of the capsules shows signs of bioincompatibility in spite of the fact that all are composed of the same material. Apparently, factors other than the purity and composition of the material play a role. Such factors might be associated with the mechanical aspects of the production process and are discussed in the following section. 


\section{The biocompatibility issue Il: adequacy of encapsulation}

The observation that only a small percentage of the capsules show cellular overgrowth after implantation suggests that physical imperfections of individual capsules might be responsible for inducing insufficient biocompatibility. Such physical defects imply inadequate encapsulation of individual islets, and thereby inadequate immune protection as well as insufficient biocompatibility.

In order to further analyse the issue of individual capsule inadequacies we first have designed an assay to identify individual islets which had been inadequately encapsulated. The assay is based on a binding of lectin and FITC labelled with RCA-I (Vector Laboratories, Burlingame, UK), and allows for quantification of the percentage of inadequately encapsulated islets under varying experimental conditions. Lectin, which has a high affinity for pancreatic islets, has a high molecular weight $(120 \mathrm{kD})$, which prevents the lectin molecules from the diffusion through the pores of an adequate microcapsule. Inadequately encapsulated islets are identified by positive fluorescence (Fig. 3), and the overall adequacy of an islet encapsulation procedure can be quantified by expressing the number of inadequate capsules as the percentage of the total number of capsules containing islets $[58,95]$.

When this assay was applied after encapsulation of Wistar rat islets using a $3 \%$ solution of Keltone LV to produce microcapsules with the usual $800 \mu \mathrm{m}$ diameter, $6.3 \pm 0.2 \%$ of the capsules was found to be inadequate. Interestingly, when the droplet generator was set to produce smaller capsules with a diameter of $500 \mu \mathrm{m}$, the percentage of inadequate capsules rose approximately fourfold to $24.2 \pm 1.5 \%$. When tested in vivo by transplanting Lewis islets encapsulated in either larger or smaller capsules into streptozotocin diabetic $\mathrm{AO} / \mathrm{G}$ rats, inadequate encapsulation was found to carry substantial significance because normoglycaemia and prolonged graft survival was obtained with the larger but not with the smaller capsules [95]. These observations are rather disturbing, because small capsules reduce diffusion distances as well as the total graft volume. The retrieval rate with peritoneal lavage was more than $80 \%$ with the larger capsules but only $5.5 \%$ with the smaller capsules. Of those retrieved capsules, only $12 \%$ of the larger capsules but $65 \%$ of the smaller capsules showed fibrotic overgrowth. Clearly, inadequate encapsulation enhances fibrotic overgrowth and reduces the chance of graft survival. The cellular overgrowth is composed of fibroproliferative connective tissue, ED-1 and ED-2 positive macrophages, T-cells but no beta cells, and occasionally some multinucleated giant cells. This composition suggests that two distinct causes are simultaneously responsible for the ob-

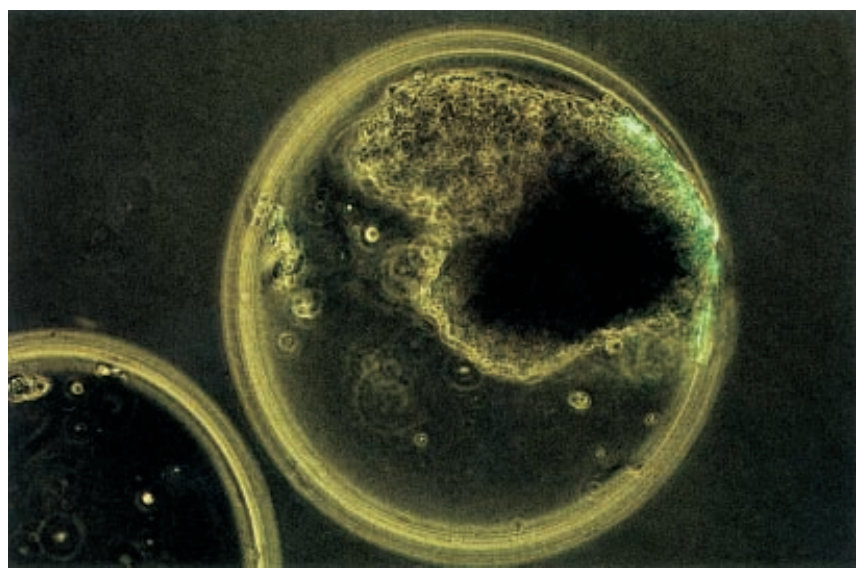

Fig. 3. Inadequate encapsulation of pancreatic islets. The islet is incompletely encapsulated. Islet cells protruding from the capsule are specifically labelled by the FITC-labelled lectin RCA-I. (original magnification $\times 100$ ). Reproduced from De Vos et al. [58] with permission of the publisher

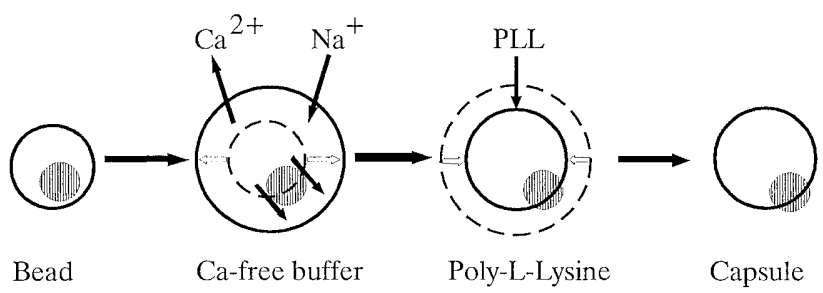

Fig. 4. Schematic presentation of the process of swelling and shrinkage during the encapsulation procedure. After gelification, the calcium-alginate beads are washed with $\mathrm{Ca}$-free $\mathrm{HRH}$ buffer, causing partial displacement of $\mathrm{Ca}$ by $\mathrm{Na}$. This process initiates the formation of an anionic interface which interacts with PLL and becomes semipermeable. The exchange of $\mathrm{Ca}$ for $\mathrm{Na}$ also induces an increase of the alginate bead diameter. As a consequence, the islets tend to be displaced towards the periphery of the alginate bead. During the subsequent step of PLL binding, shrinkage occurs while islets maintain their peripheral location and consequently tend to readily protrude from their capsules. Reproduced from De Vos et al. [58] with permission of the publisher

served reaction. One is that the islet, by its incomplete protection, induces an allograft reaction. The other is that the inadequate capsule itself, by its broken integrity, induces a foreign body reaction.

Factors other than diameters could also influence the adequacy of the microcapsules. When Manugel (55\% G-content) instead of Keltone LV (45\% Gcontent) alginate is used to produce the smaller type of $500 \mu \mathrm{m}$ capsules, the percentage of inadequate capsules decreases from $24 \%$ to $12 \%$. The different results with Keltone LV and Manugel alginates are related to differences in swelling and subsequent shrinkage properties during the consecutive steps of the encapsulation procedure [58] (Fig. 4). The higher $\mathrm{G} / \mathrm{M}$ ratio of Manugel is associated with less swelling, which is associated with a reduced chance for islets to 


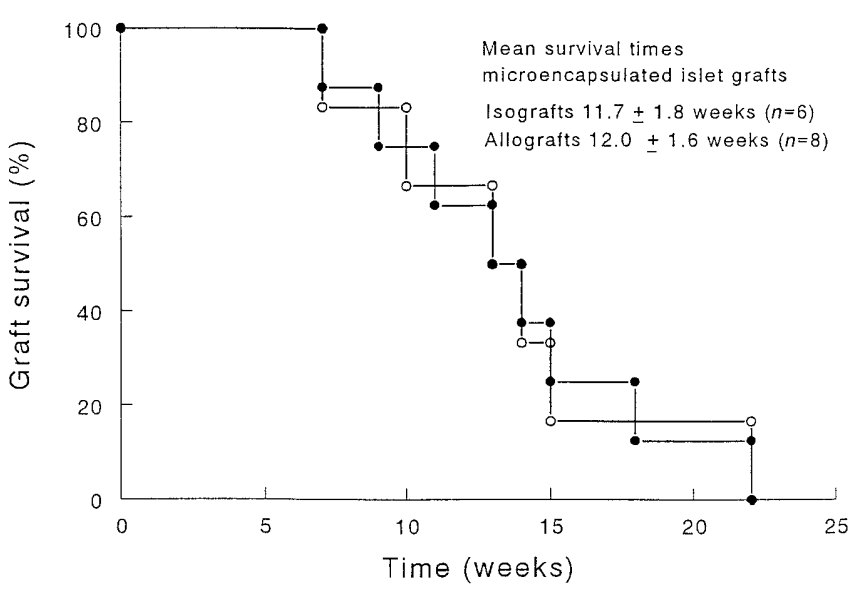

Fig. 5. Survical of encapsulated islet isografts ( $n=6$, open symbols) and allografts ( $n=8$, closed symbols) in streptozotocin diabetic AO-rats. Note the similar if not identical survival times

protrude and, consequently, inadequate encapsulation. Apparently, alginates with a high $\mathrm{G} / \mathrm{M}$ ratio should be applied to reduce the percentage of inadequate capsules.

In conclusion, to provide complete immunoprotection and optimal biocompatibility, application of purified and fully biocompatible material is not enough; the capsule production process itself should result in mechanically adequate microcapsules. This is an important consideration because variable factors like the capsule diameter and the type of alginate were shown to influence these mechanics.

\section{Functional performance of microencapsulated islet grafts}

Intraperitoneal transplantation of a microencapsulated islet graft restored normoglycaemia in streptozotocin diabetic rat recipients within 1 week after transplantation. This normalization of blood glucose concentrations was associated with an evident metabolic improvement as illustrated by a normalization of body weight gain and by a dramatic reduction in daily urine production. Regretfully, however, graft functional survival times were limited and hyperglycaemia returned between 5 and 16 weeks after transplantation $[59,95]$. These results were confirmed in later experiments with survival times of 6 to 20 weeks, which were similar if not identical in isografts and allografts [59] (Fig. 5). This latter observation proves that rejection was not the cause of graft failure. Graft failure could not be explained either by fibrotic overgrowth and subsequent cell death because this was observed in only a small minority of capsules as described above. It could also not have been caused by insufficient viability of isolated islets because isogenically transplanted naked, non-encap-

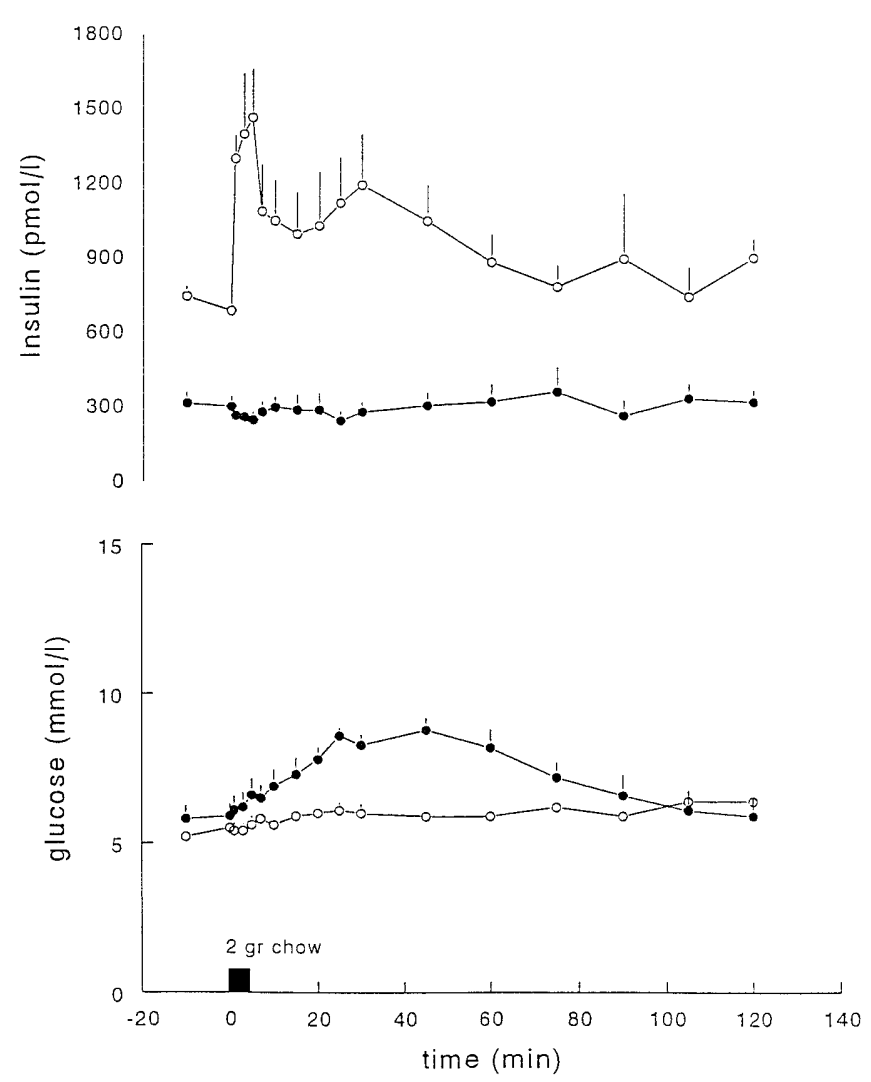

Fig. 6. Blood glucose and plasma insulin levels after spontaneous ingestion of a meal $(n=5)$ in AO-recipients of microencapsulated islet allografts (closed symbols) and in normal control rats (open symbols). The animals were trained to consume a meal of 2 gram chow within 5 mins. Values represent means \pm SEM

sulated islets survived after intraperitoneal implantation [96].

When functioning grafts were tested by oral or intravenous glucose challenge, glucose tolerance was found to be rather adequate as indicated by normal $\mathrm{HBA}_{\mathrm{c} 1}$ levels and maximum glucose levels of $8.3 \mathrm{mmol} / \mathrm{l}$ after the consumption of a glucose-rich meal but a rise in systemic insulin was never observed (Fig. 6).

We have further substantiated this observation experimentally by assessing portal and systemic insulin responses and glucose concentrations after gradual infusion of low amounts of insulin into the peritoneal cavity, thereby mimicking the gradual release of insulin from the capsules of an intraperitoneal graft. We found that the dose-dependent rise of insulin and decrease of glucose levels with intraperitoneal insulin infusion were strongly delayed and reduced as well as prolonged in comparison to intraportal insulin infusion [70, 97] (Fig. 7).

In the subsequent experiments on function of intraperitoneally transplanted microencapsulated islets, we assessed C-peptide in the systemic circulation instead of insulin. C-peptide is released in equimolar 


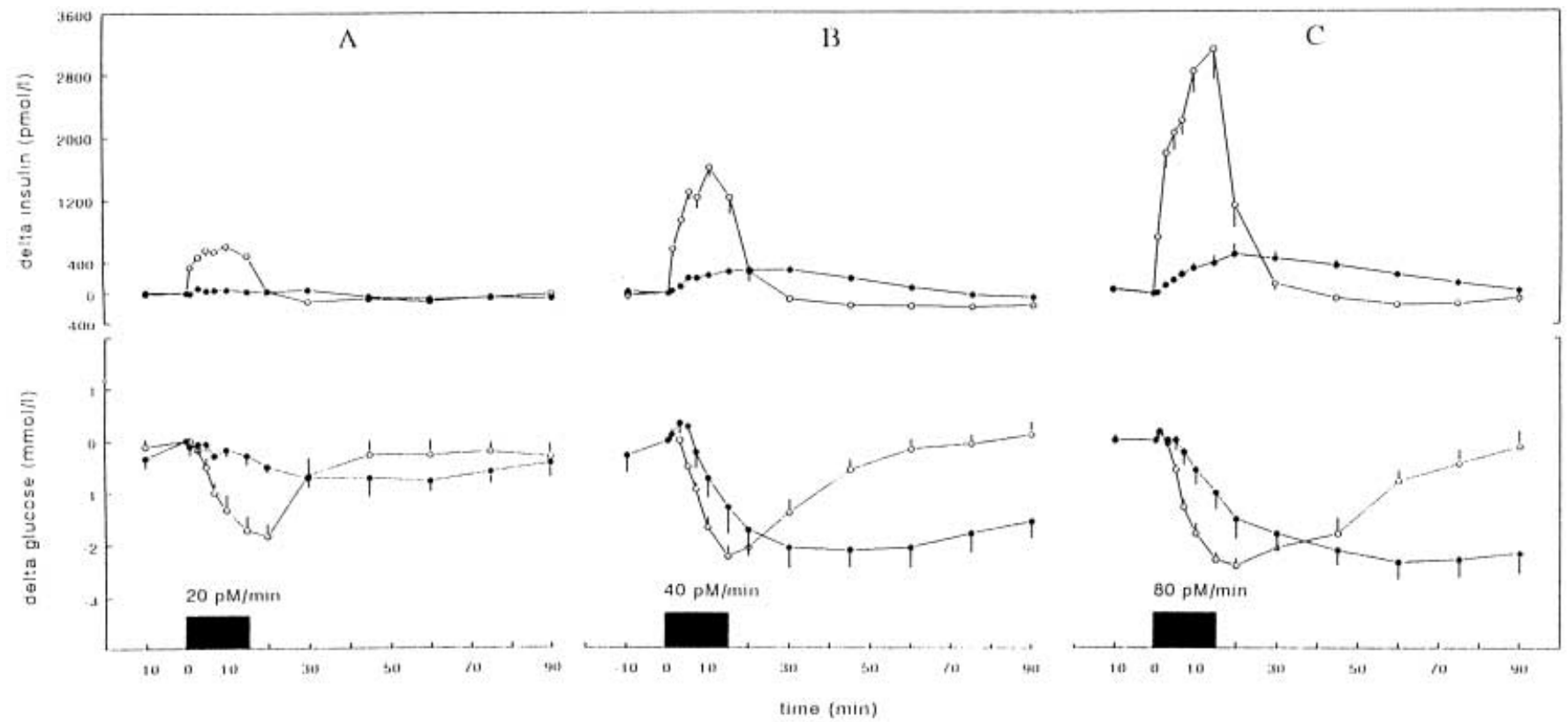

Fig. 7. Effect of intraperitoneal $(\bigcirc)$ and intraportal $(\bigcirc)$ infusion of different concentrations of insulin on plasma insulin and glucose concentrations. Insulin was infused in a dose of $20 \mathrm{pmol} \cdot \mathrm{l}^{-1} \cdot \min ^{-1}(\mathbf{A}, n=6), 40 \mathrm{pmol} \cdot \mathrm{l}^{-1} \cdot \min ^{-1}(\mathbf{B}, n=5)$, and $80 \mathrm{pmol} \cdot \mathrm{l}^{-1} \cdot \min ^{-1}(\mathbf{C}, n=7)$, during $15 \mathrm{~min}$. The dose of $20 \mathrm{pmol} \cdot \mathrm{1}^{-1} \cdot \mathrm{min}^{-1}$ induces a rise in systemic insulin concentrations after portal infusion similar to that observed in AOrats consuming a meal. Values are means \pm SEM of levels expressed as delta levels with the $t=0$ level as the zero reference. Reproduced from De Vos et al [70] with permission of the publisher

concentrations with insulin, is not readily absorbed by the abdominal organs and does not undergo hepatic extraction. With this approach, we have found a glucose-induced response from the encapsulated islets as shown by an increase of C-peptide in systemic circulation when diabetic mice were subjected to meal challenge [71]. The increase, however, was delayed when compared to normal non-diabetic control mice (Fig. 8 A). Generally, when compared to the normal control mice, the C-peptide levels in plasma were considerably lower in the mice transplanted with either naked or encapsulated islets. In accordance with this lower C-peptide production, we observed a reduced body growth rate in the mice transplanted with either naked or encapsulated islets. Surprisingly, glucose clearance was about the same as that of mice transplanted with naked islets (Fig. 8 B). Similar delay and relatively low response of C-peptide during intravenous glucose tolerance test were reported in NOD mice transplanted with microencapsulated islets [68]. One potential explanation of that phenomenon is that the peritoneal cavity is known to be less accommodating to transplanted islets. It has been shown that naked syngeneic islets transplanted under the kidney capsule or into the portal vein of diabetic rats were much more efficient in normalising glucose concentrations than when transplanted into the peritoneal cavity [96, 98, 99]. Additionally, islets in microcapsules in the absence of the vascularization of a graft, could be exposed to relative hypoxia $[11,100]$.

\section{A vascularized transplantation site for microencapsulated islets}

The absence of revascularization of the encapsulated islets interferes with both the functional performance and the longevity of the grafts. Apparently, a site where encapsulated islets are in close contact with the blood stream is obligatory for clinical application. Unfortunately, it is difficult to find such a site because it should combine the capacity to bear a large graft volume in the immediate vicinity of blood vessels. Reported sites allowing for successful islet transplantation such as the liver [101-104], the spleen [101, 105-107], and the renal capsule [20, 108, 109] do not meet these requirements because they can never carry the volumes of more than $100 \mathrm{ml}$ of capsules required for transplantation in human beings $[44,87,110]$. To overcome this obstacle, we recently introduced the concept of an intraperitoneally implanted solid support system for pancreatic islets [111]. This site allows for implantation of high numbers of islets, which can readily be retrieved and, theoretically, can be designed to be highly vascularized.

We developed a solid support system of expanded PTFE (ePTFE) because ePTFE have been shown to be biocompatible and to become neovascularized after implantation in the peritoneal cavity. Initially, we 

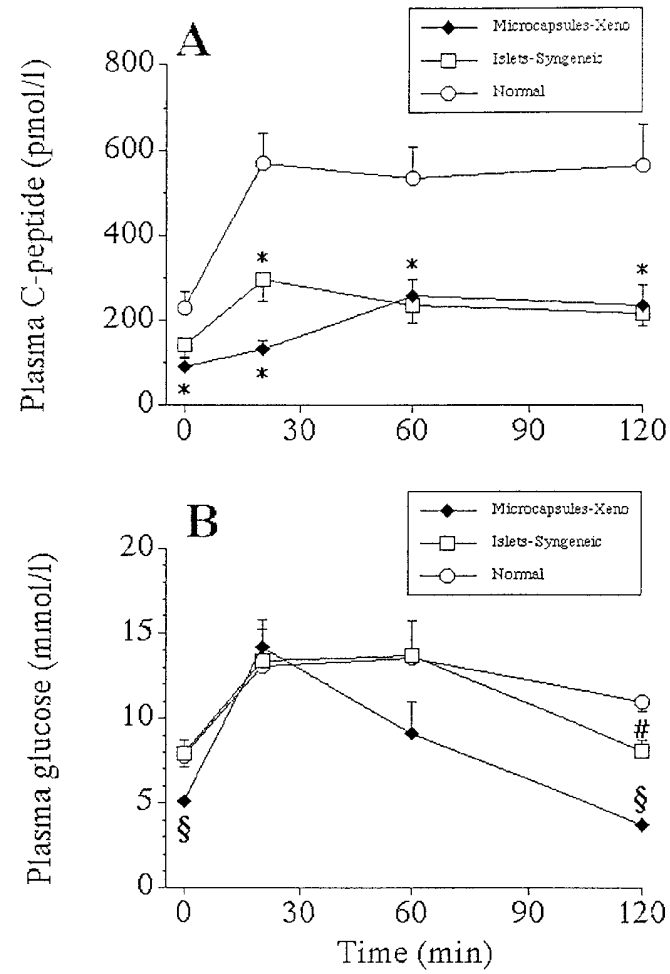

Fig. 8(A, B). Meal challenge performed 9 weeks after intraperitoneal transplantation of either microencapsulated xenogeneic rat islets $(n=7)$ or syngeneic non-encapsulated mouse islets $(n=5)$ into STZ diabetic B6 $\mathrm{AF}_{1}$ mice. A Plasma C-peptide concentrations and $\mathbf{B}$ plasma glucose concentrations during a meal challenge. As controls, age-matched normal non-diabetic $\mathrm{B}_{6} \mathrm{AF}_{1}$ mice were used $(n=9)$. Data are presented as means $\pm \mathrm{SEM} ; * p<0.01$ microcapsules and syngeneic vs normal, $\beta p<0.02$ microcapsules vs normal and syngeneic, $\# p<0.001$ syngeneic vs normal. Reproduced from Tatarkiewicz et al. [71] with permission of the publisher

applied solid supports coated with collagen type IV (ie. the collagen type predominantly present in the basal membrane) and acidic-fibroblast growth factors (a-FGF) to facilitate the ingrowth of blood vessels [111-113]. These supports were always implanted 4 weeks before the introduction of the islets to prevent islet dysfunction as the consequence of inflammatory reaction against the ePTFE - a reaction which is usually complete within 4 weeks [111]. Before implanting encapsulated islets, we tested the efficacy of these ePTFE solid support systems as a transplantation site for naked, non-encapsulated islet graft by comparing the functional performance of islet isografts implanted in the solid supports to those implanted in the unmodified peritoneal cavity. These experiments indicate that the solid supports were much more efficacious than the unmodified peritoneal cavity because when we implanted $10 \mu \mathrm{l}$ of islet tissue in the solid support we found that all rat recipients became normoglycaemic while only $40 \%$ with transplantation of the islets in the unmodified peritoneal cavity did [111].
In the subsequent histological evaluation of the solid supports, we assessed the degree of vascularization of the grafts and compared it with the vascularization of the liver. The liver was chosen because it is an organ allowing for successful transplantation of islets both in experimental animals and in human beings [101, 109, 114, 115]. Unfortunately, we found that the degree of vascularization of the solid supports was far behind that of the liver. Another observation illustrating the inadequate vascularization of the supports was that transplantation of an suboptimal non-encapsulated islet volume of $5 \mu \mathrm{l}$, ie. half the volume of the islet tissue present in the pancreas of a control rat, was associated with normoglycaemia in $60 \%$ of the recipients while it was $100 \%$ after grafting in the liver [111].

In our subsequent studies on vascularization of solid supports, we focussed on VEGF-165 [116-118], which is considered to have the greatest potential as an angiogenic stimulus when compared to other angiogenic growth factors such as acidic-fibroblast growth factor, basic-fibroblast growth factor, platelet-derived growth factor, epidermal growth factor, epidermal growth factor, alpha and beta transforming growth factor, interleukines (IL-8 and TNF) or prostaglandines.

Our approach to stimulate vascularization by administration of angiogenic factors is shown in Figure 9. Firstly, angiogenic stimuli degrade the basal membrane and components of the extracellular matrix around capillaries in the immediate vicinity of the solid support. Subsequently, the endothelial cells start to proliferate and migrate into the site of release of the angiogenic factors. Finally, the endothelial cells form tubular structures after which they differentiate into cells aligning full mature blood vessels. The whole sequence of events leading to the formation of blood vessels is under control of a wide variety of angiogenic growth factors which are endogenously produced by cells in the immediate vicinity of the solid supports.

Figure 10 shows our present experimental approach to stimulate vascularization of the solid supports applicable for encapsulated islets. These supports were prepared from flat sheets of ePTFE which were coated with collagen type IV and subsequently implanted in the peritoneal cavity in the immediate vicinity of the liver in order to promote portal drainage of insulin. The supports were infused with a solution of saline containing VEGF-165 and heparin (to stabilize the VEGF).

After 4 weeks of infusion with VEGF-165, we found, macroscopically, much more blood vessels running over and into the supports when compared to injections of aFGF. Subsequent staining with RECA-1 (ie. a specific rat endothelial cell marker), showed a degree of vascularization of $66 \pm 8$ vessels/ $\mathrm{mm}^{2}$ in VEGF-165 treated supports (at a dose of 80 


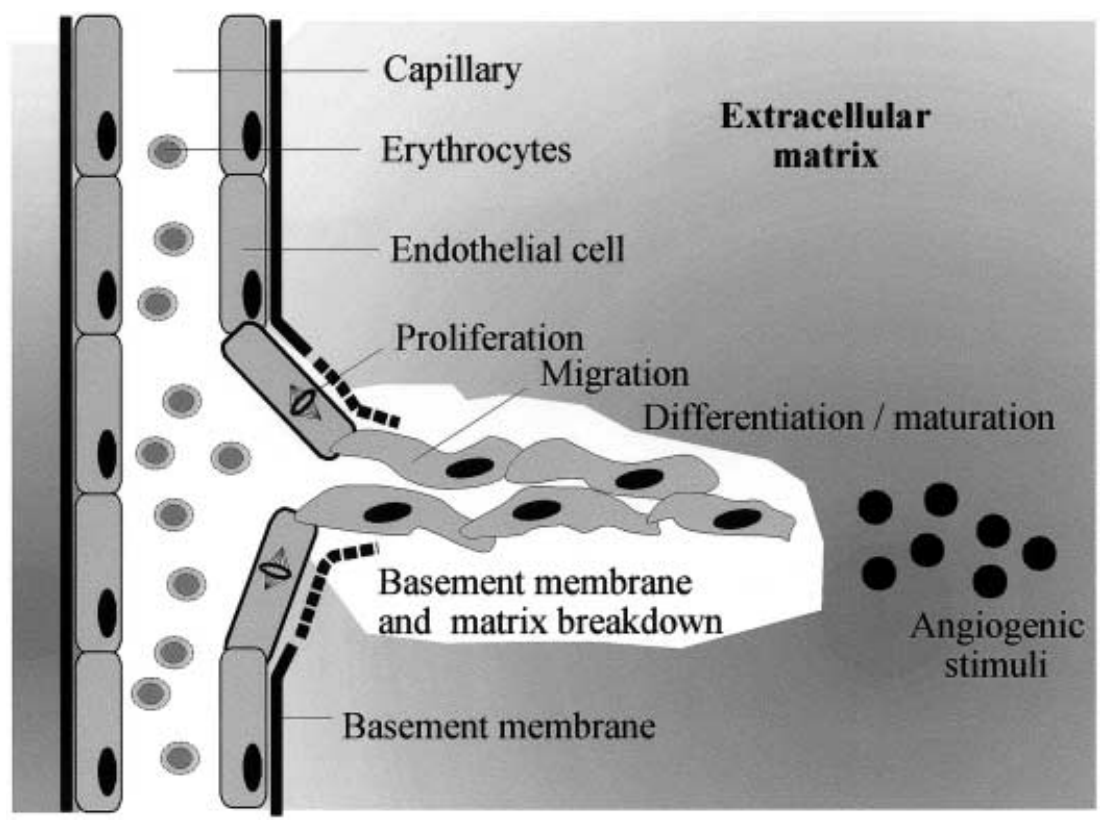

Fig.9. The process of angiogenesis after exogenous administration of angiogenic stimuli. Basal membrane and matrix degradation facilitates the migration of proliferation endothelial cells to the angiogenic stimulus

$\mathrm{ng}$ /day) which was similar to the $72 \pm 7$ vessels $/ \mathrm{mm}^{2}$ found in the liver. Control supports, ie. supports infused with saline and heparin in the absence of VEGF-165, showed a lower degree of vascularization of $44 \pm 12$ vessels $/ \mathrm{mm}^{2}$.

At present we are exploring the possibility of repeated replacement of encapsulated islet grafts from VEGF-165-treated supports because this could be mandatory for clinical application in case of limited function of encapsulated grafts. This is done by injecting encapsulated islets into the supports in a solution of alginate with a high-M content. These high-M alginates chelify in the human body and therefore can keep the capsules at its place in the solid support. If replacement is required the high- $\mathrm{M}$ alginates can easily be solved by the administration of Ca-gelators such as EGTA. Liquification of the solution allows aspiration of the alginate in combination with the encapsulated islets in a procedure, which requires only minor surgery.

\section{Longevity of microencapsulated islets}

As follows from the preceding sections, minor modifications in the encapsulation procedure could have an important impact on the capsule's biocompatibility and thus on the functional outcome of the graft. However, the factors contributing to the quality of microcapsules are not standardized. As a conse- quence, there are many different encapsulation procedures, each resulting in capsules with different porosities and with specific chemical and mechanical characteristics. Obviously, these differences contribute to the enormous variations in reported success rates of encapsulated islet allografts and xenografts.

It has been assumed that indefinite survival would be achieved with islet-containing microcapsules which elicit a minimal foreign body reaction $[78,87$, 119]. However, even when the foreign body reaction affected only an insignificant number of capsules $[59,91]$, long-term survival of the encapsulated islet grafts in rats was not achieved. This phenomenon of graft failure in the absence of overgrowth of the capsules has been reported before [120-122] and is usually explained by exhaustion of the graft as a consequence of a combination of a too high glycaemic load on an insufficient number of transplanted encapsulated islets. In our studies in rats, however, neither the volume of the graft nor the glycaemic load on the islets caused graft failure. We found that after transplantation of a sufficient islet volume of $10 \mu \mathrm{l}$, the functional mass of the graft decreased rapidly not only in diabetic but also in normoglycaemic recipients.

Some dispute excist as to the effect of the ongoing activity of the immunological rejection process on the survival of immunoprotected islets. It has been shown that cytotoxic antibodies can be formed against the islets in spite of the presence of a capsule around the tissue $[16,29,123,124]$. It has also been shown that cytokines produced during the rejection process, such as IL- $1 \beta$ can pass through the capsule membrane [125]. In our in vivo studies, we found no effect of the histoincompatibility of the encapsulated islets on the graft survival because isograft had identical survival times as allografts [59]. These findings 


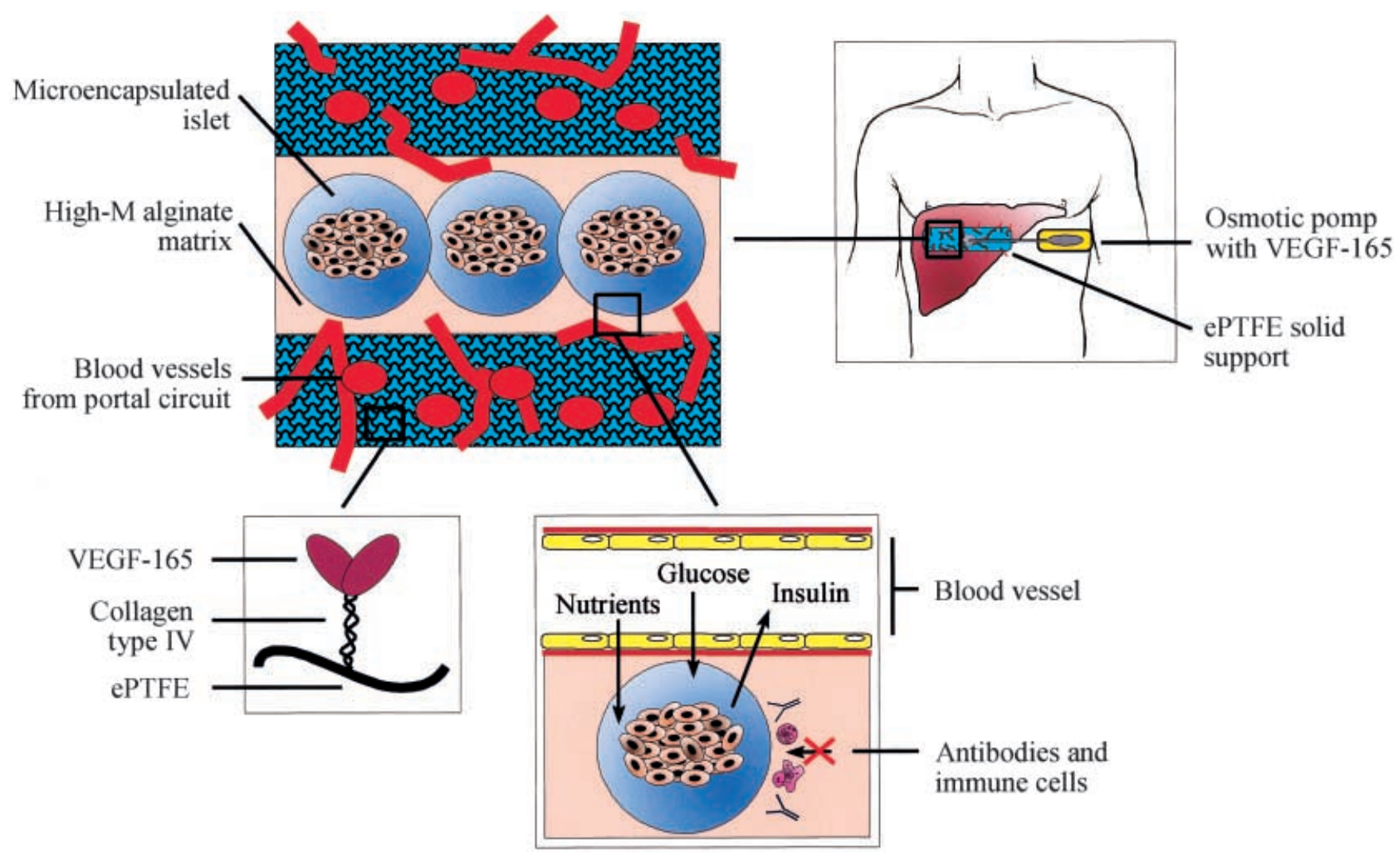

Fig. 10. Schematic presentation of the principle of grafting of encapsulated islets in prevascularized solid support systems. ePTFE solid supports are coated with collagen type IV and subsequently implanted in the peritoneal cavity. The solid supports are infused with an ALZET osmotic pump for 4 weeks with VEGF-165 in order to stimulate the ingrowth of blood vessels. The collagen type IV functions as a matrix to prevent the VEGF-165 from immediate diffusion into the surroundings. After 4 weeks, the osmotic pump is removed and alginate-PLL encapsulated islets are infused in a solution of high$\mathrm{M}$ alginate (which forms a gel in the presence of the physiological $\mathrm{Ca}$-concentration) to keep the encapsulated islets at their place in the solid support

suggest that capsules can adequately protect against the allograft reactions initiated by the encapsulated islets after transplantation.

Our results suggest that the long-term graft survival might depend on the access of encapsulated tissue to blood supply and, consequently, on sufficient supply of nutrition and/or growth factors delivered to the encapsulated islets. Although this issue is not covered by the current definition [126], it should be considered to be a biocompatibility problem because long-term survival of the tissue is required for this specific application but, regretfully, is not compatible with the presence of the biomaterial around the tissue.

\section{Concluding remarks}

It is clear that important advances have been made in immunoisolation of pancreatic islets during the last few decades. This view is corroborated by the results of the restricted experience obtained in human beings [21, 44, 127]. Very few reports from clinics on transplantation of encapsulated islets might be explained by not only scientific reasons. Limited availability of human islets, recent concerns about using pig tissue in humans, and extremely high expenses probably contribute to sluggish progress in clinical application of microencapsulation approach. In view of the recent successful transplantation of pancreatic stem cells [128-130], one might expect unlimited sources of allogeneic insulin-producing tissue in the near future. Additionally, enhanced survival of grafts supported by induced neovascularization might result in encapsulation technology which will be the ultimate solution to cure Type I diabetes.

Sources. This review is based on the relevant literature published in the English language during the period 1980-2001, and seminal prior contributions. The sources available to the authors were integrated with sources identified through PubMed searches for "encapsulation of pancreatic islets" and "vascularization and transplantation of microencapsulated islets".

Acknowledgements. K. Tatarkiewicz was supported by a research fellowship grant from the Juvenile Diabetes Research 
Foundation. P. de Vos received research grants from the Dutch Diabetes Foundation and the Dutch Society for Scientific Research (NWO). C.G. Weir is acknowledged for his critical comments on the manuscript.

\section{References}

1. The effect of intensive treatment of diabetes on the development and progression of long-term complications in insulin-dependent diabetes mellitus. (1993) The Diabetes Control and Complications Trial Research Group. N Engl J Med 329: 977-986

2. Robertson RP, Davis C, Larsen J, Stratta R, Sutherland DE (2000) Pancreas and islet transplantation for patients with diabetes. Diabetes Care 23: 112-116

3. Sutherland DE, Gruessner AC, Gruessner RW (1998) Pancreas transplantation: a review. Transplant Proc 30: 1940-1943

4. Kronson JW, Gillingham KJ, Sutherland DE, Matas AJ (2000) Renal transplantation for type II diabetic patients compared with type I diabetic patients and patients over 50 years old: a single-center experience. Clin Transpl 14: 226-234

5. Knazek RA, Gullino PM, Kohler PO, Dedrick RL (1972) Cell culture on artificial capillaries: an approach to tissue growth in vitro. Science 178: 65-66

6. Chick WL, Like AA, Lauris V (1975) Beta cell culture on synthetic capillaries: an artificial endocrine pancreas. Science 187: 847-849

7. Scharp DW, Mason NS, Sparks RE (1984) Islet immunoisolation: the use of hybrid artificial organs to prevent islet tissue rejection. World J Surg 8: 221-229

8. Chick WL, Like AA, Lauris V et al. (1975) A hybird artifical pancreas. Trans Am Soc Artif Intern Organs 21: 8-15

9. Sun AM, Parisius W, Healy GM, Vacek I, Macmorine HG (1977) The use, in diabetic rats and monkeys, of artificial capillary units containing cultured islets of Langerhans (artificial endocrine pancreas). Diabetes 26: 1136-1139

10. Maki T, Lodge JP, Carretta M et al. (1993) Treatment of severe diabetes mellitus for more than one year using a vascularized hybrid artificial pancreas. Transplantation 55: 713-717

11. Colton CK (1995) Implantable biohybrid artificial organs. Cell Transplant 4: 415-436

12. Galletti PM, Trudell LA, Panol G, Richardson PD, Whittemore A (1981) Feasibility of small bore AV shunts for hybrid artificial organs in nonheparinized beagle dogs. Trans Am Soc Artif Intern Organs 27: 185-187

13. Colton CK, Avgoustiniatos ES (1991) Bioengineering in development of the hybrid artificial pancreas. J Biomech Eng 113: 152-170

14. Archer J, Kaye R, Mutter G (1980) Control of streptozotocin diabetes in Chinese hamsters by cultured mouse islet cells without immunosuppression: a preliminary report. J Surg Res 28: 77-85

15. Loudovaris T, Jacobs S, Young S, Maryanov D, Brauker J, Johnson RC (1999) Correction of diabetic nod mice with insulinomas implanted within Baxter immunoisolation devices. J Mol Med 77: 219-222

16. Lanza RP, Beyer AM, Chick WL (1994) Xenogeneic humoral responses to islets transplanted in biohybrid diffusion chambers. Transplantation 57: 1371-1375

17. Jain K, Asina S, Yang H et al. (1999) Glucose control and long-term survival in biobreeding/Worcester rats after intraperitoneal implantation of hydrophilic macrobeads containing porcine islets without immunosuppression. Transplantation 68: 1693-1700

18. Lacy PE, Hegre OD, Gerasimidi Vazeou A, Gentile FT, Dionne KE (1991) Maintenance of normoglycaemia in diabetic mice by subcutaneous xenografts of encapsulated islets. Science 254: 1782-1784

19. Juang JH, Bonner-Weir S, Vacanti JP, Weir GC (1995) Outcome of subcutaneous islet transplantation improved by a polymer device. Transplant Proc 27: 3215-3216

20. Juang JH, Bonner-Weir S, Wu YJ, Weir GC (1994) Beneficial influence of glycaemic control upon the growth and function of transplanted islets. Diabetes 43: 1334-1339

21. Scharp DW, Swanson CJ, Olack BJ et al. (1994) Protection of encapsulated human islets implanted without immunosuppression in patients with type I or type II diabetes and in nondiabetic control subjects. Diabetes 43: $1167-1170$

22. Suzuki K, Bonner-Weir S, Trivedi N et al. (1998) Function and survival of macroencapsulated syngeneic islets transplanted into streptozocin-diabetic mice. Transplantation 66: $21-28$

23. Suzuki K, Bonner-Weir S, Hollister-Lock J, Colton CK, Weir GC (1998) Number and volume of islets transplanted in immunobarrier devices. Cell Transplant 7: 47-52

24. Tatarkiewicz K, Hollister-Lock J, Quickel RR, Colton CK, Bonner-Weir S, Weir GC (1999) Reversal of hyperglycemia in mice after subcutaneous transplantation of macroencapsulated islets. Transplantation 67: 665-671

25. Siebers U, Zekorn T, Bretzel RG et al. (1990) Histocompatibility of semipermeable membranes for implantable diffusion devices (bioartificial pancreas). Transplant Proc 22: $834-835$

26. Algire GH (1943) An adaption of the transparant chamber technique to the mouse. J Natl Cancer Inst 4: 1-11

27. Klomp GF, Ronel SH, Hashiguchi H, D'Andrea M, Dobelle WH (1979) Hydrogels for encapsulation of pancreatic islet cells. Trans Am Soc Artif Intern Organs 25: 74-76

28. Kessler L, Pinget M, Aprahamian M, Dejardin P, Damge C (1991) In vitro and in vivo studies of the properties of an artificial membrane for pancreatic islet encapsulation. Horm Metab Res 23: 312-317

29. Lanza RP, Ecker D, Kühtreiber WM, Staruk JE, Marsh J, Chick WL (1995) A simple method for transplanting discordant islets into rats using alginate gel spheres. Transplantation 59: 1485-1487

30. Woodward SC (1982) How fibroblasts and giant cells encapsulate implants: considerations in design of glucose sensors. Diabetes Care 5: 278-281

31. Lanza RP, Borland KM, Lodge P et al. (1992) Pancreatic islet transplantation using membrane diffusion chambers. Transplant Proc 24: 2935-2936

32. Shoichet MS, Winn SR, Athavale S, Harris JM, Gentile FT (1994) Poly(ethylene oxide)-grafted thermoplastic membranes for use as cellular hybrid bio-artificial organs in the central nervous system. Biotech Bioeng 43: $563-572$

33. Metrakos P, Yuan S, Qi SJ, Duguid WP, Rosenberg L (1994) Collagen gel matrix promotes islet cell proliferation. Transplant Proc 26: 3349-3350

34. Metrakos P, Yuan S, Agapitos D, Rosenberg L (1993) Intercellular communication and maintenance of islet cell mass- implications for islet transplantation. Surgery 114: 423-427

35. Lanza RP, Butler DH, Borland KM et al. (1992) Successful xenotransplantation of a diffusion-based biohybrid artificial pancreas: a study using canine, bovine, and porcine islets. Transplant Proc 24: 669-671 
36. Lanza RP, Sullivan SJ, Chick WL (1992) Perspectives in diabetes. Islet transplantation with immunoisolation. Diabetes 41: 1503-1510

37. Lanza RP, Chick WL (1995) Encapsulated Cell Therapy. Scientific American Science and Medicine 4: 16-25

38. Lanza RP, Hayes JL, Chick WL (1996) Encapsulated cell technology. Biotechnology 14: 1107-1111

39. Lanza RP, Kuhtreiber WM, Ecker DM, Marsh JP, Staruk JE, Chick WL (1996) A simple method for xenotransplanting cells and tissues into rats using uncoated alginate microreactors. Transplant Proc 28: 835

40. Iwata H, Takagi T, Amemiya H (1992) Agarose microcapsule applied in islet xenografts (hamster to mouse). Transplant Proc 24: 952

41. Sefton MV (1993) The good, the bad and the obvious: 1993 Clemson Award for Basic Research-Keynote Lecture. Biomaterials 14: 1127-1134

42. Kessler L, Legeay G, Jesser C, Damgé C, Pinget M (1995) Influence of corona surface treatment on the properties of an artificial membrane used for Langerhans islets encapsulation: Permeability and biocompatibility studies. Biomaterials 16: 185-191

43. Kessler L, Legeay G, West R, Belcourt A, Pinget M (1997) Physicochemical and biological studies of coronatreated artificial membranes used for pancreatic islets encapsulation: Mechanism of diffusion and interface modification. J Biomed Mater Res 34: 235-245

44. Soon Shiong P, Heintz RE, Merideth N et al. (1994) Insulin independence in a type 1 diabetic patient after encapsulated islet transplantation. Lancet 343: 950-951

45. Sun YL, Ma XJ, Zhou DB, Vacek I, Sun AM (1996) Normalization of diabetes in spontaneously diabetic cynomologus monkeys by xenografts of microencapsulated porcine islets without immunosuppression. J Clin Invest 98: 1417-1422

46. Calafiore R, Basta G, Luca G et al. (1999) Transplantation of pancreatic islets contained in minimal volume microcapsules in diabetic high mammalians. Ann NY Acad Sci 875: vol

47. Weber CJ, Safley S, Hagler M, Kapp J (1999) Evaluation of graft-host response for various tissue sources and animal models. Ann NY Acad Sci 875: 233-254

48. Cruise GM, Hegre OD, Lamberti FV et al. (1999) In vitro and in vivo performance of porcine islets encapsulated in interfacially photopolymerized poly(ethylene glycol) diacrylate membranes. Cell Transplant 8: 293306

49. Kulseng B, Skjak-Braek G, Ryan L et al. (1999) Transplantation of alginate microcapsules: generation of antibodies against alginates and encapsulated porcine isletlike cell clusters. Transplantation 67: 978-984

50. Calafiore R, Basta G, Osticioli L, Luca G, Tortoioli C, Brunetti P (1996) Coherent microcapsules for pancreatic islet transplantation: A new approach for bioartificial pancreas. Transplant Proc 28: 812-813

51. Grohn P, Klock G, Schmitt J et al. (1994) Large-scale production of $\mathrm{Ba}(2+)$-alginate-coated islets of Langerhans for immunoisolation. Exp Clin Endocrinol Diabetes 102: 380-387

52. Siebers U, Zekorn T, Horcher A et al. (1994) Microencapsulated transplantation of allogeneic islets into specifically presensitized recipients. Transplant Proc 26: 787-788

53. Zimmermann U, Klöck G, Federlin K et al. (1992) Production of mitogen-contamination free alginates with variable ratios of mannuronic acid to guluronic acid by free flow electrophoresis. Electrophoresis 13: 269-274
54. Ar'Rajab A, Bengmark S, Ahren B (1991) Insulin secretion in streptozotocin-diabetic rats transplanted with immunoisolated islets. Transplantation 51: 570-574

55. Basic D, Vacek I, Sun AM (1996) Microencapsulation and transplantation of genetically engineered cells: A new approach to somatic gene therapy. Artif Cells Blood Substit Immobil Biotechnol 24: 219-255

56. Chicheportiche D, Reach G (1988) In vitro kinetics of insulin release by microencapsulated rat islets: effect of the size of the microcapsules. Diabetologia 31: 54-57

57. Crooks CA, Douglas JA, Broughton RL, Sefton MV (1990) Microencapsulation of mammalian cells in a HEMA-MMA copolymer: effects on capsule morphology and permeability. J Biomed Mater Res 24: 1241-1262

58. De Vos P, De Haan BJ, Wolters GHJ, Van Schilfgaarde R (1996) Factors influencing the adequacy of microencapsulation of rat pancreatic islets. Transplantation 62: 888-893

59. De Vos P, De Haan BJ, Wolters GHJ, Strubbe JH, Van Schilfgaarde R (1997) Improved biocompatibility but limited graft survival after purification of alginate for microencapsulation of pancreatic islets. Diabetologia 40 : 262-270

60. Iwata H, Amemiya H, Matsuda T, Takano H, Hayashi R, Akutsu T (1989) Evaluation of microencapsulated islets in agarose gel as bioartificial pancreas by studies of hormone secretion in culture and by xenotransplantation. Diabetes 38 [Suppl 1]: 224-225

61. Korbutt GS, Elliott JF, Ao Z, Flashner M, Warnock GL, Rajotte RV (1997) Microencapsulation of neonatal porcine islets: Long-term reversal of diabetes in nude mice and in vitro protection from human complement mediated cytolysis. Transplant Proc 29: 2128

62. Sandler S, Andersson A, Eizirik DL et al. (1997) Assessment of insulin secretion in vitro from microencapsulated fetal porcine islet-like cell clusters and rat, mouse, and human pancreatic islets. Transplantation 63: 1712-1718

63. Stevenson WT, Sefton MV (1987) Graft copolymer emulsions of sodium alginate with hydroxyalkyl methacrylates for microencapsulation. Biomaterials 8: 449-457

64. Sun AM (1997) Advantages of microencapsulation as an immunoprotection method in the transplantation of pancreatic islets. Ann Transplant 2: 55-62

65. Yderstroede KB (1987) Pancreatic islet transplantation. Experimental and clinical aspects. Dan Med Bull 34: 323-329

66. Zhou M, Chen D, Yao Q, Xia Z, Wang C, Zhu H (1998) Microencapsulation of rat islets prolongs xenograft survival in diabetic mice. Chin Med J (Engl) 111: 394-397

67. Halle JP, Leblond FA, Pariseau JF, Jutras P, Brabant MJ, Lepage Y (1994) Studies on small ( $<300$ microns) microcapsules: II-Parameters governing the production of alginate beads by high voltage electrostatic pulses. Cell Transplant 3: 365-372

68. Duvivier-Kali VF, Omer A, Parent RJ, O'Neil JJ, Weir GC (2001) Complete protection of islets against allorejection and autoimmunity by a simple barium-alginate membrane. Diabetes 50: 1698-1705

69. De Vos P, Vegter D, Strubbe JH, De Haan BJ, Van Schilfgaarde R (1997) Impaired glucose tolerance in recipients of an intraperitoneally implanted microencapsulated islet allograft is caused by the slow diffusion of insulin through the peritoneal membrane. Transplant Proc 29: 756-757

70. De Vos P, Vegter D, De Haan BJ, Strubbe JH, Bruggink JE, Van Schilfgaarde R (1996) Kinetics of intraperitoneally infused insulin in rats: functional implications for the bioartificial pancreas. Diabetes 45: 1102-1107 
71. Tatarkiewicz K, Garcia M, Omer A, Van Schilfgaarde R, Weir GC, De Vos P (2001) C-peptide responses after meal challenge in mice transplanted with microencapsulated rat islets. Diabetologia 44: 646-653

72. De Vos P, Van Schilfgaarde R (1999) Biocompatibility Issues. In: Kühtreiber WM, Lanza RP, Chick WL (eds) Cell encapsulation technology and therapeutics. Birkhäuser, Boston, pp 63-79

73. Lim F, Sun AM (1980) Microencapsulated islets as bioartificial endocrine pancreas. Science 210: 908-910

74. Wells GD, Fisher MM, Sefton MV (1993) Microencapsulation of viable hepatocytes in HEMA-MMA microcapsules: a preliminary study. Biomaterials 14: 615-620

75. Bartkowiak A, Canaple L, Ceausoglu I et al. (1999) New multicomponent capsules for immunoisolation. Ann NY Acad Sci 875: 135-145

76. Rihova B (2000) Immunocompatibility and biocompatibility of cell delivery systems. Adv Drug Deliv 42: 65-80

77. Fritschy WM, Wolters GH, Van Schilfgaarde R (1991) Effect of alginate-polylysine-alginate microencapsulation on in vitro insulin release from rat pancreatic islets. Diabetes 40: $37-43$

78. Klock G, Frank H, Houben R et al. (1994) Production of purified alginates suitable for use in immunoisolated transplantation. Appl Microbiol Biotechnol 40: 638-643

79. Kulseng B, Thu T, Espevik T, Skjåk-Bræk G (1997) Alginate polylysine microcapsules as immune barrier: permeability of cytokines and immunoglobulins over the capsule membrane. Cell Transplant 6: 387-394

80. Sawhney AS, Hubbell JA (1992) Poly(ethylene oxide)graft-poly(L-lysine)copolymers to enhance the biocompatibility of poly(L-lysine)-alginate micocapsules membranes. Biomaterials 13: 863-870

81. Bystricky S, Malovikova A, Sticzay T (1991) Interaction of acid polysaccharides with polylysine enantiomers, conformation probe in solution. Carbohydrate Polymers 15: 299-308

82. Bystricky S, Malovikova A, Sticzay T (1990) Interaction of alginate and pectins with cationic polypeptides. Carbohydr Res 13: 283-294

83. King GA, Daugulis AJ, Faulkner P, Goosen MFA (1987) Alginate-Polylysine Microcapsules of Controlled Membrane Molecular Weight Cutoff for Mammalian Cell Culture Engineering. Biotechnol.Prog. 3: 231-240

84. Vandenbossche GM, Van Oostveldt P, Remon JP (1991) A fluorescence method for the determination of the molecular weight cut-off of alginate-polylysine microcapsules. J Pharm Pharmacol 43: 275-277

85. Vandenbossche GM, Bracke ME, Cuvelier CA, Bortier HE, Mareel MM, Remon JP (1993) Host reaction against alginate-polylysine microcapsules containing living cells. J Pharm Pharmacol 45: 121-125

86. Vandenbossche GM, Bracke ME, Cuvelier CA, Bortier HE, Mareel MM, Remon JP (1993) Host reaction against empty alginate-polylysine microcapsules. Influence of preparation procedure. J Pharm Pharmacol 45: $115-120$

87. De Vos P, Wolters GH, Fritschy WM, Van Schilfgaarde R (1993) Obstacles in the application of microencapsulation in islet transplantation. Int J Artif Organs 16: 205-212

88. Van Schilfgaarde R, De Vos P (1999) Factors influencing the properties and performance of microcapsules for immunoprotection of pancreatic islets. J Mol Med 77: 199-205

89. Uludag H, de-Vos P, Tresco PA (2000) Technology of mammalian cell encapsulation. Adv Drug Deliv Rev 42: 29-64
90. De Vos P, De Haan B, Van Schilfgaarde R (1997) Effect of the alginate composition on the biocompatibility of alginate-polylysine microcapsules. Biomaterials 18: 273-278

91. De Vos P, van Straaten JF, Nieuwenhuizen AG et al. (1999) Why do microencapsulated islet grafts fail in the absence of fibrotic overgrowth? Diabetes 48: 1381-1388

92. Otterlei M, Ostgaard K, Skjåk-Bræk G, Smidsrod O, Soon-Shiong P, Espevik T (1991) Induction of cytokine production from human monocytes stimulated with alginate. J Immunother 10: 286-291

93. Espevik T, Otterlei M, Skjåk-Bræk G, Ryan L, Wright SD, Sundan A (1993) The involvement of CD14 in stimulation of cytokine production by uronic acid polymers. Eur J Immunol 23: 255-261

94. Strand BK, Ryan L, In 't Veld P et al. (2001) Poly-L-lysine induces fibrosis on alginate microcapsules via the induction of cytokines. Cell Transplant 10: 263-277

95. De Vos P, De Haan BJ, Pater J, Van Schilfgaarde R (1996) Association between capsule diameter, adequacy of encapsulation, and survival of microencapsulated rat islet allografts. Transplantation 62: 893-899

96. Fritschy WM, van Straaten JF, De Vos P, Strubbe JH, Wolters GH, Van Schilfgaarde R (1991) The efficacy of intraperitoneal pancreatic islet isografts in the reversal of diabetes in rats. Transplantation 52: 777-783

97. De Vos P, De Haan BJ, Vegter D et al. (1998) Insulin levels after portal and systemic insulin infusion differ in a dose-dependent fashion. Horm Metab Res 30: 721-725

98. Okugawa K, Fukuda Y, Sakimoto H et al. (1996) Intermittent intraperitoneal implantation of islets in rat islet transplantation. Cell Transplant 5: S51-S53

99. Kemp CB, Knight MJ, Scharp DW, Ballinger WF, Lacy PE (1973) Effect of transplantation site on the results of pancreatic islet isografts in diabetic rats. Diabetologia 9: 486-491

100. Avgoustiniatos ES, Colton CK (1997) Effect of external oxygen mass transfer resistances on viability of immunoisolated tissue. Ann NY Acad Sci 31: 145-167

101. van Suylichem PT, Strubbe JH, Houwing H, Wolters GH, Van Schilfgaarde R (1994) Rat islet isograft function. Effect of graft volume and transplantation site. Transplantation 57: 1010-1017

102. Gardemann A, Jungermann K, Grosse V et al. (1995) Reinnervation of pancreatic islets and regulation of insulin secretion by hepatic sympathetic nerves after intraportal transplantation of islets into livers of diabetic rats. Exp Clin Endocrinol Diabetes 103 [Suppl. 2]: 107-111

103. Andersson A, Korsgren O, Jansson L (1989) Intraportally transplanted pancreatic islets revascularized from hepatic arterial system. Diabetes 38 [Suppl 1]: 192-195

104. Dunger A, Korsgren O, Andersson A (1990) DNA replication in mouse pancreatic islets transplanted subcapsularly into the kidney or intraportally into the liver. Influence of unilateral nephrectomy or partial hepatectomy. Transplantation 49: 686-689

105. Kneteman NM, Warnock GL, Evans MG, Nason RW, Rajotte RV (1990) Prolonged function of canine pancreatic fragments autotransplanted to the spleen by venous reflux. Transplantation 49: 679-681

106. Feldman SD, Hirshberg GE, Dodi G et al. (1977) Intrasplenic islet isografts. Surgery 82: 386-394

107. Beattie GM, Hayek A (1993) Islet cell mass and the longevity of islet grafts in diabetic rats. Cell Transplant 2: 119-122

108. Ar'Rajab A, Ahren B, Alumets J, Logdberg L, Bengmark S (1990) Islet transplantation to the renal subcapsular 
space improves late complications in streptozotocin-diabetic rats. Eur Surg Res 22: 270-278

109. van Suylichem PT, Strubbe JH, Houwing H, Wolters GH, Van Schilfgaarde R (1992) Insulin secretion by rat islet isografts of a defined endocrine volume after transplantation to three different sites. Diabetologia 35: 917-923

110. De Vos P, De Haan BJ, Van Schilfgaarde R (1997) Upscaling the production of encapsulated islets. Biomaterials 18: 1085-1090

111. De Vos P, Hillebrands JL, De Haan BJ, Strubbe JH, Van Schilfgaarde R (1997) Efficacy of a prevascularized expanded polytetrafluoroethylene solid support system as a transplantation site for pancreatic islets. Transplantation 63: 824-830

112. Thompson JA, Haudenschild CC, Anderson KD, DiPietro JM, Anderson WF, Maciag T (1989) Heparin-binding growth factor 1 induces the formation of organoid neovascular structures in vivo. Proc Natl Acad Sci USA 86: 7928-7932

113. Thompson JA, Anderson KD, DiPietro JM et al. (1988) Site-directed neovessel formation in vivo. Science 241: 1349-1352

114. Carroll PB, Rilo HL, Alejandro R et al. (1995) Long-term ( > 3-year) insulin independence in a patient with pancreatic islet cell transplantation following upper abdominal exenteration and liver replacement for fibrolamellar hepatocellular carcinoma. Transplantation 59: 875-879

115. Shapiro AM, Lakey JR, Ryan EA et al. (2000) Islet transplantation in seven patients with type 1 diabetes mellitus using a glucocorticoid-free immunosuppressive regimen. N Engl J Med 343: 230-238

116. Trivedi N, Steil GM, Colton CK, Bonner-Weir S, Weir GC (2000) Improved vascularization of planar membrane diffusion devices following continuous infusion of vascular endothelial growth factor. Cell Transplant 9: 115-124

117. Neufeld G, Cohen T, Gengrinovitch S, Poltorak Z (1999) Vascular endothelial growth factor (VEGF) and its receptors. FASEB J 13: 9-22

118. Frelin C, Ladoux A, D'angelo G (2000) Vascular endothelial growth factors and angiogenesis. Ann Endocrinol (Paris) 61: 70-74

119. Zekorn T, Klöck G, Horcher A et al. (1992) Lymphoid activation by different crude alginates and the effect of purification. Transplant Proc 24: 2952-2953
120. O'Shea GM, Sun AM (1986) Encapsulation of rat islets of langerhans prolongs xenograft survival in diabetic mice. Diabetes 35: 943-946

121. Lum ZP, Krestow M, Tai IT, Vacek I, Sun AM (1992) Xenografts of rat islets into diabetic mice. Transplantation 53: $1180-1183$

122. Nielsen JH (1985) Growth and function of the pancreatic B-cell in vitro. Effect of glucose, hormones and serum factors on mouse, rat and human pancreatic islets in organ culture. Acta Endocrinol 108: 1-40

123. Lanza RP, Kuhtreiber WM, Beyer A, Chick WL (1994) Humoral response to encapsulated islets. Transplant Proc 26: $3346-3347$

124. Lanza RP, Chick WL (1997) Immunoisolation: At a turning point. Immunol Today 18: 135-139

125. Kulseng B, Thu B, Espevik T, Skjak Braek G (1997) Alginate polylysine microcapsules as immune barrier: permeability of cytokines and immunoglobulins over the capsule membrane. .Cell Transplant 6: 387-394

126. Williams DF (1987) Summary and definitions. In: Anonymous progress in biomedical engineering: Definition in biomaterials. Elsevier Science Publisher BV, Amsterdam, pp 66-71

127. Brunetti P, Basta G, Faloerni A, Calcinaro F, Pietropaolo M, Calafiore R (1991) Immunoprotection of pancreatic islet grafts within artificial microcapsules. Int J Artif Organs 14: 789-791

128. Soria B, Roche E, Berna G, Leon-Quinto T, Reig JA, Martin F (2000) Insulin-secreting cells derived from embryonic stem cells normalize glycemia in streptozotocininduced diabetic mice. Diabetes 49: 157-162

129. Soria B, Andreu E, Berna G et al. (2000) Engineering pancreatic islets. Pflugers Arch 440: 1-18

130. Ramiya VK, Maraist M, Arfors KE, Schatz DA, Peck AB, Cornelius JG (2000) Reversal of insulin-dependent diabetes using islets generated in vitro from pancreatic stem cells. Nat Med 6: 278-282

131. Zielinski BA, Aebischer P (1994) Chitosan as a matrix for mammalian cell encapsulation. Biomaterials 15: 1049-1056

132. Dawson RM, Broughton RL, Stevenson WT, Sefton MV (1987) Microencapsulation of CHO cells in a hydroxyethyl methacrylate- methyl methacrylate copolymer. Biomaterials 8: 360-366 